be significantly higher than that reported. In one survey, published in American Scientist in 1993, for example, between six and nine per cent of respondents said they were personally aware of results that had been plagiarized or fabricated within their faculties.

A survey in 1995 of nearly 300 randomly selected researchers in Norway revealed that 22 per cent of respondents were aware of 'serious breaches of research ethical guidelines', with nine per cent reporting that they had personally contributed to such serious breaches. Nearly 60 per cent said they were aware of less serious misconduct within their faculties. Yet the Norwegian Committee on Scientific Dishonesty has had only nine cases referred to it since it was established in 1994 - only two of which were found to have substance.

Whatever the true level of scientific misconduct, most agree that prevention is a priority. Kenneth J. Ryan chaired the Commission on Research Integrity which reviewed US policy on scientific misconduct in the mid-1990s at the request of Congress. He says that the commission's remit "was not a question of punishment, which is what most scientists worry about, but of the integrity of science - how to teach people and to prevent misconduct".

This is certainly the prevailing view in Europe, where many scientists have watched with dismay how investigations of alleged fraud in the United States have become increasingly protracted, demanding sub-

\title{
Japanese scandals raise public distrust
}

Very few cases of scientific fraud have come to light in Japan. Some attribute this to instrinsic honesty among Japanese scientists, but others say it may merely reflect a national culture in which people turn a blind eye to issues that could give rise to social tensions.

The hierarchical structure of university faculties, particularly within the old, conservative 'imperial' universities, and the autocratic powers of individual professors, certainly discourage scientists from blowing the whistle on dubious scientific practices.

"Whistle-blowing is rare, and those bold enough to make accusations do not walk off unscathed - they may well lose their jobs," says Masanori Kaji, a historian of science at Tokyo Institute of Technology.

In addition, young scientists cannot hope to influence suspect scientific practice inside the laboratory. "Under the koza system at Japanese universities, where each research group is led by a powerful professor, junior members of staff have almost no voice in the way research is carried out."

As a government white paper (policy document) on nuclear energy research pointed out last year, however, public trust in science in general has plummeted in the stantial amounts of time from the scientists who become involved.

\section{Over-due process?}

Like most organizations in Europe except Denmark — both the NIH and the US National Science Foundation (NSF) rely on the academic institutions that receive their research funds to investigate allegations of misconduct in the first instance, and then to report their findings to the funding agency. Agency officials then review the institution's findings, investigate further if necessary, and recommend appropriate sanctions.

Keeping the primary investigations at the institutional level affords important protection to those accused. But it can also create an enormous burden for the institutions themselves. An investigating committee may spend many months analysing notebooks containing raw data and interviewing witnesses, a process than can be particularly taxing in the United States when the accused brings in an aggressive defence lawyer.

So it can take years to reach a final decision. Pre-agreed time limits are frequently waived by both parties when they become unrealistic. Lawyers for the accused may attack the integrity of the individual who makes the accusation, issue legal challenges to the investigating committee members or university administrators, or accuse whistle-blowers of inappropriate personal relationships.

past few years following a series of nuclear accidents and subsequent cover-ups, including fabrication of research data at nuclear fuel recycling plants.

The white paper said that people perceived scientists as "insular" and "unwilling to disclose or share details of their research due to preoccupation with successful results".

As a result of such incidents, scientists are under increasing pressure to take the ethical aspects of research more seriously. Nearly half of the respondents in a recent public survey conducted by Kanazawa Institute of Technology said they did not believe that scientists have higher moral values than the rest of the population. Ninety-five per cent thought scientists should take more responsibility for the way they work and how they communicate the details of their research to the public.

So, despite the apparently low incidence of scientific misconduct in Japan, broader scepticism towards ethical conduct in research is relatively high. Partly in response, the Science Council of Japan - a government advisory group - published a report last year calling for a new system to promote good scientific practice at universities.

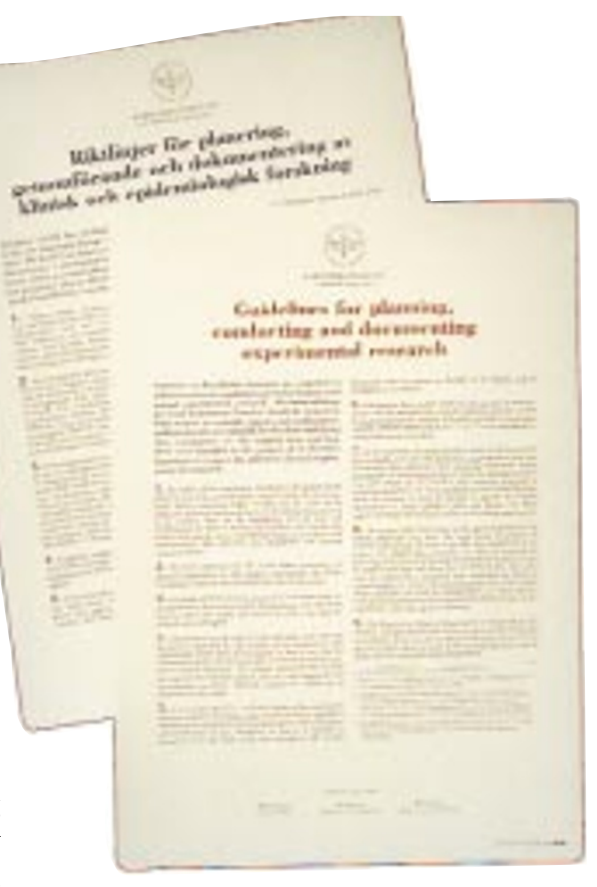

Straight and narrow: the Scandinavians were among the first to develop research guidelines.

A lawyer defending a researcher suspected of misconduct in California once hired a private investigator to produce a psychological profile of the dean handling the investigation, based on a letter he had written to the accused, labelling the dean as paranoid.

Such tactics have persuaded some administrators and scientists that they would never again participate in such investigations. William R. Brinkley, a dean at Baylor College of Medicine in Houston, Texas, and president of the Federation of American Societies of Experimental Biology (FASEB), has observed a long-running misconduct case at his own institution (Nature 383, 107; 1996). "The toll it takes is enormous," he says. "People get wrapped up in these cases for years. They have told me they couldn't afford to do it again; it destroys their careers."

The experience is having a significant impact on how fraud allegations are handled. Until recently, scientists, defence attorneys and professional societies all stressed the importance of ensuring due process for the accused - a reaction to the fact that this had not been afforded during some cases in the 1980s. But many now question whether the pendulum has swung too far the other way. They are asking whether accused researchers have been granted so much due process that institutions are deterred from investigating allegations, so facilitating a climate in which a corrupt scientist might go unpunished - or even unchallenged.

Even the current president of FASEB, which has longled the demand for maximum due process for accused scientists, acknowledges that "the duplication of the [current] process wears everyone out". "We may well have built in too much due process," says 